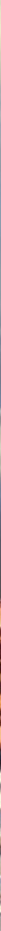

A lion guards Beijing's Forbidden City as a symbol of strength. China's capital is itself a stronghold of scientific achievement, along with Shanghai and Nanjing.

\title{
THREE GIANTS TIGHTEN THEIR GRIP
}

\section{The benefits of economics and history converge with the demands of population growth and sustainability issues in China's most productive research and technology centres.}

\section{BY PENG TIAN}

$\mathrm{I}$ $\mathrm{t}$ will come as no surprise that the top performing Chinese cities in the Nature Index are Beijing, Shanghai and Nanjing. All three are significant players economically and politically, Beijing and Shanghai particularly.

At all levels of Chinese government, officials see innovation through science and technology as critical for the nation to achieve continued economic growth on a more environmentally sustainable path. The central government has invested heavily in science and technology to improve productivity and upgrade some industries, such as the manufacture of advanced high-speed trains.

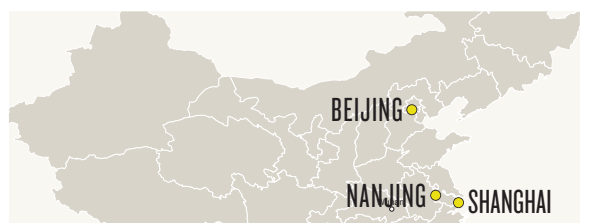

This, in turn, has reinforced the status of Beijing, Shanghai and Nanjing, which represent the Chinese cities with the top 2014 WFCs. (see 'China's top 10').

The local governments of advanced provinces also push technological innovation to achieve economic ascendancy over other cities. Market forces are playing an increas$\begin{array}{ll}\text { "Along period } & \text { ingly significant role in } \\ \text { Beijing, Shanghai and }\end{array}$ growthhas national and domestic beenmirrored commercial enterprises by committed work with universities to investment." develop next-generation technologies.

Crucially, China's research system was significantly rebuilt after the turmoil of the Cultural Revolution - the social and political movement that began in 1966.

A long period of economic growth has been mirrored by committed investment in science and technology. Besides the National Natural Science Foundation of China (NSFC), there are several ongoing programmes that promote basic research and technological innovations in universities and institutes. These have included the 863 and 973 Programmes under the Ministry of Science and Technology (MOST), and Projects 211 and 985 under the Ministry of Education. Through these initiatives elite universities and institutes in Beijing, Shanghai and Nanjing have received enormous funding support to build advanced research facilities and improve research quality.

\section{BEIJING}

$\checkmark$ Direction shows position change 2013-2014

\section{$\Rightarrow$ WFC rank China: 1}

त $A C: 5,163$

Beijing, the nation's capital, has been the centre of power for China for millennia, and a research and industry stronghold since the foundation of the People's Republic of China in 1949.

Beijing benefits most from the systems of resource allocation established after 1949 when the communist government restructured and relocated the country's main education and research centres.

It has the highest number of institutions in the Nature Index - 131 in 2014 - of the three 


\section{CHINA'S TOP 10}

The country's most productive cities in the Nature Index by WFC in 2014.

WFC
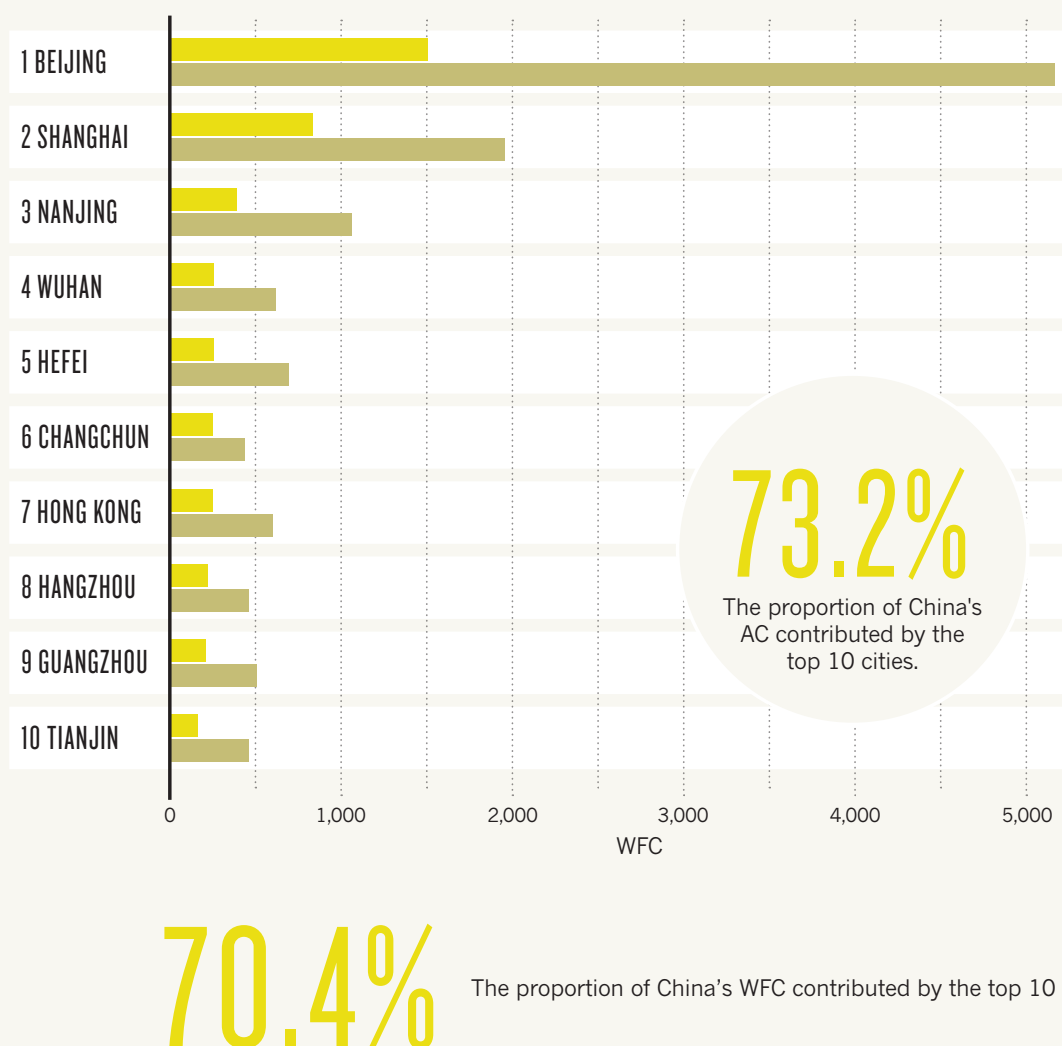

The proportion of China's WFC contributed by the top 10 cities.

cities and is particularly strong in chemistry and physical sciences. This contributes greatly to Beijing's overall output in the Nature Index. Beijing has also inherited some of the most prestigious universities established prior to 1949. These include China's leading Peking University (PKU) and Tsinghua University, which receive resources from central and local governments. Several

\section{“PKU's special} position in China has played a key role in helping us get support from the central government." significant institutes of the behemoth Chinese Academy of Sciences (CAS), such as the Institute of Chemistry and Institute of Physics, are also located in Beijing. Between

them, Beijing's top 10 institutions accounted for around $60 \%$ of the city's overall 2014 WFC (see 'Cities of influence').

The vast resources allocated to these universities have paved the way for some groundbreaking research, including an important development in quantum computing by Duan Luming from Tsinghua University. In a paper published in Nature, he and colleagues described experiments that bring robust quantum computation at room temperature closer to reality.

Generous funding has also helped physicist Peng Lianmao at Peking University, who is developing technology that can build carbon nanotube semiconductor devices and integrated circuits. In a paper published in Applied Physics Letters, his team detailed the construction of

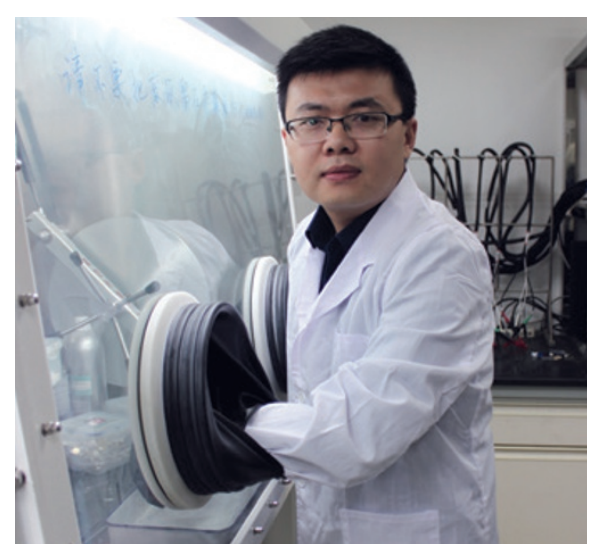

Wang Yonggang focuses on new lithium batteries.

\section{CITIES OF INFLUENCE}

Beijing hosts the most institutions, while Shanghai and Nanjing's WFC comes largely from their top 10 performers.

\section{All institutions \\ Top 10}

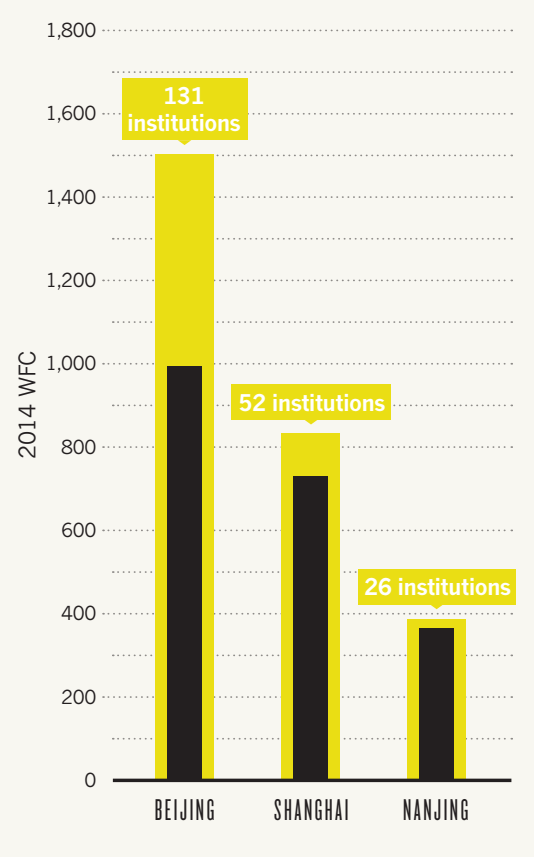

high-performance carbon nanotube transistors and integrated circuits, which represents the future of computer processors. This work received funds from the MOST, NSFC, and the Beijing Municipal Science and Technology Commission

"The research work of constructing nano devices and integrated circuits needs huge funding," Peng says. Since 2011, his lab has received about 70 million $\mathrm{RMB}$ from Project 973. "PKU's special position in China has played a key role in helping us to get support from the central government."

Now, he says, the lab is the only one in the world that can construct $10-n m$ carbon nanotube complementary metal-oxide-semiconductor (CMOS) integrated circuits. In 2012, the application potential of this attracted local government money from the Beijing Municipal Science and Technology Commission. "Beijing Municipality is helping us to make some longterm development strategies for carbon-based integrated circuits," Peng explains. He is optimistic that a clear strategy and further funding will come through at the national level to take the technology even further. 


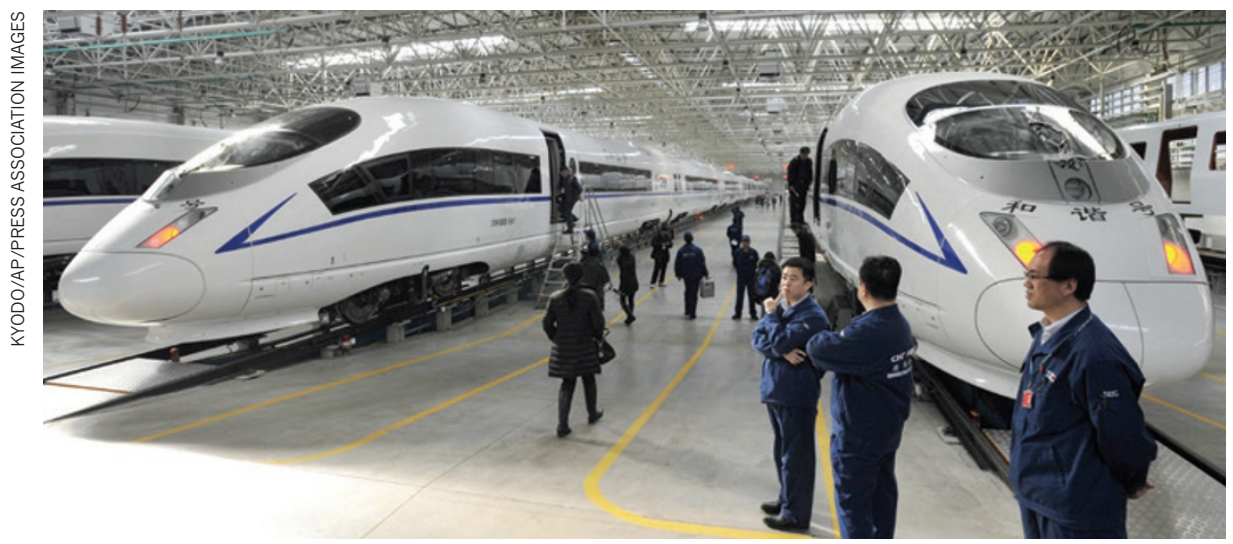

The manufacture of advanced high-speed trains has attracted significant government funding.

\section{SHANGHAI}

\section{$\rightarrow$ WFC rank China: 2}

A AC: 1,955

In an idyllic location on the estuary of the great Yangtze River in the centre of East China's Yangtze River Delta, Shanghai has become a world-renowned port and global financial hub since it opened to international trade in the 1840s. Shanghai, which has been one of the world's major manufacturing centres for more than two decades, receives generous research resources from the regional economy.

With a 2014 population of more than 24 million, Shanghai is now the largest and most populous city in China. It has the prestigious Fudan University as well as many research institutes of the CAS and other universities built after 1949 .

Shanghai has less than half the total number of institutions of Beijing in the index - 52 in 2014 - but its top 10 produce a similar output to the capital's top 10. Shanghai's strength lies in chemistry (see 'Shanghai's best game'). More

\section{SHANGHAI'S BEST GAME}

Relative subject area strength as a proportion of overall WFC in 2014.

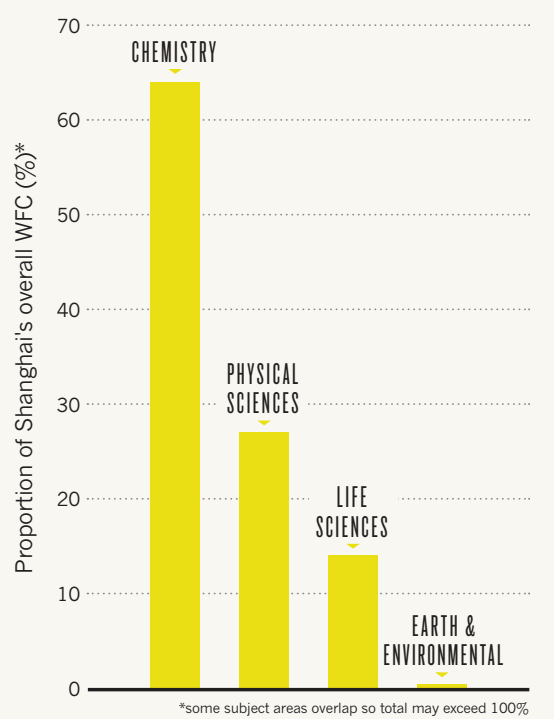

than $60 \%$ of the city's output in the Nature Index is in chemistry, and Fudan University and the CAS Shanghai Institute of Organic Chemistry are the biggest contributors.

"Besides the promotion from the state and Shanghai, international corporations, giant state-owned enterprises, and private enterprises also actively collaborate with Shanghai's universities and research institutes to develop new technologies," says Wang Yonggang, a materials chemist and associate professor in the Department of Chemistry at Fudan University. Between 20 and $30 \%$ of his lab's funding comes from such collaborations.

Wang's research focuses on new types of lithium battery. He's already had some promising results published in Chemical Communications, which show that these devices have the potential to be next-generation batteries for everything from electric cars to smartphones.

Wang is a partner of the Collaborative Innovation Center of Chemistry for Energy Materials (iChEM), a project of Plan 2011. "The centre can coordinate experts from different research fields, make communication more efficient, and has the capacity for commercializing the achievements", Wang explains.

\section{NANJING \\ $\rightarrow$ WFC rank China: 3 \\ A AC: 1,064}

As the capital of the wealthy eastern coastal province of Jiangsu, Nanjing is located in a region rich in economic and technological activity.

Nanjing means 'southern capital' in Chinese - an indication of its status - and is the second largest city after Shanghai in the prosperous Yangtze River Delta. In recent years, Nanjing's largest growth across all the subject areas has, as with Shanghai, been in chemistry. Also like Shanghai, almost $60 \%$ of its output in the Nature Index is in chemistry. In an effort to differentiate itself from its regional counterpart, grants to promote materials science and astrophysics have been offered to research groups in Nanjing.

Nanjing University is the main source of the city's scientific discovery and technological innovations and the city's main contributor

\section{LEADING THE PACK}

Nanjing's overall growth is driven by the performance of a single institution.
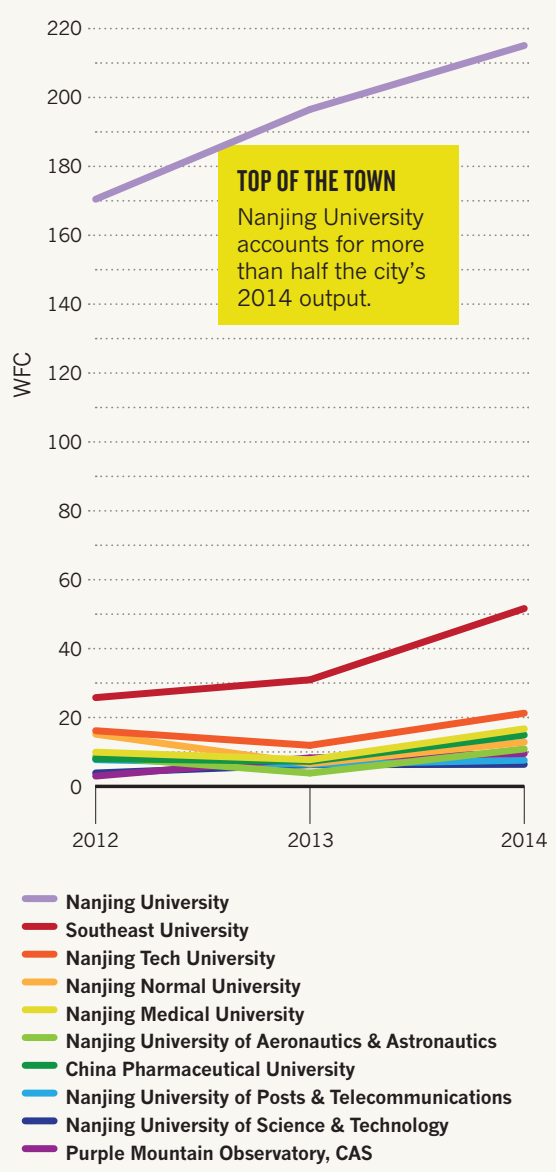

to the Nature Index, accounting for more than half of Nanjing's overall 2014 output (see 'Leading the pack'). The Collaborative Innovation Center of Advanced Microstructures (CICAM),
"We always try to extend the limits of knowledge. Now we want to translate the breakthroughs." which is part of Plan 2011, generates most of Nanjing's research on artificial microstructure materials. As well as basic research, this centre also tries to translate research findings into practical applications to meet the technological needs of the delta's industries.

CICAM acoustic physicist Bin Liang, a professor at Nanjing University, has designed and experimentally realized a new acoustic absorption material that may be used for noise reduction and to make echo-free underwater materials. His research was recently published in Applied Physics Letters.

Not so long ago the acoustic qualities of this new material were thought to be impossible to achieve, Bin says. "We always think about trying to extend the limits of knowledge," he explains. "Now, we want to translate the breakthroughs into applications." - 